\title{
Effects of subjective sleep quality on the quality of life in patients with chronic anorectal disorder
}

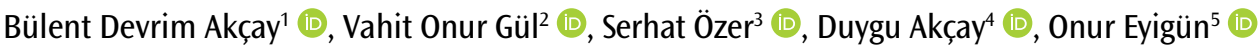

ORCID IDs of the authors: B.D.A. 0000-0002-6308-9327; V.O.G. 0000-0001-9071-0732; S.0.0000-0003-3468-1839; D.A. $0000-0001-9030-6879$; 0.E. 0000-0002-3736-9122.

Objective: The aim of the present study was to evaluate the subjective sleep quality in patients with anorectal disorder, to determine the factors associated with subjective sleep quality, and to explore the relationship between subjective sleep quality and quality of life.

Material and Methods: This descriptive study was conducted between April 8, 2015 and April 12, 2016. The research population consisted of 284 patients who attended the general surgery outpatient clinics of Konya Military Hospital and were subsequently diagnosed with one of the four most common anorectal disorders (hemorrhoidal disease, anal fissure, anorectal abscess/fistula, and sacrococcygeal pilonidal disease). Data were collected from 114 patients who volunteered to participate in the study. After establishment of the diagnosis based on proctological anamnesis and physical examination, the Pittsburgh Sleep Quality Index, Short-Form Health Survey, Beck Anxiety Inventory, and Beck Depression Inventory were administered to the patients, along with a questionnaire on sociodemographic data, via a face-to-face interview technique.

Results: Ninety-six (84.2\%) patients had poor sleep quality, whereas $18(15.8 \%)$ patients had good sleep quality. Among the patients with poor sleep quality, 16 were diagnosed with anorectal abscess and fistula (100.0\%), 40 with hemorrhoidal disease (90.9\%), 16 with sacrococcygeal pilonidal disease (80.0\%), and 24 with anal fissure (70.6\%). Overall, all patients with poor sleep quality $(n=96)$ had low scores in all subcomponents of the quality of life scale.

Conclusion: The sleep quality in patients with chronic anorectal disorder is significantly impaired, thus negatively affecting quality of life. Therefore, improvement in quality of life by improving sleep quality should be one of the main objectives in treating chronic anorectal disorders.
\end{abstract}

\section{Cite this paper as:} Akçay, BD, Gül V0, ÖzerS, Akçay D, Eyigün 0 . Effects of subjective sleep quality on the quality of life in patients with chronic anorectal disorder. Turk J Surg 2018; 34(4): 276-281.

'Department of Psychiatry Gülhane Training and Research Hospital, Ankara, Turkey

${ }^{2}$ Department of General Surgery, Gülhane Training and Research Hospital, Ankara, Turkey

${ }^{3}$ Unit of Intensive Care, Gülhane Training and Research Hospital, Ankara, Turkey

${ }^{4}$ Ministry of National Defense, Ankara, Turkey

${ }^{5}$ Department of Psychiatry, Edremit State Hospital, Ankara, Turkey

\section{Corresponding Author} Bülent Devrim Akçay e-mail:drbulentakcay@yahoo.com

Received: 30.08.2017 Accepted: 02.01.2018

Available Online Date: 13.09.2018

\section{CCopyright 2018} by Turkish Surgical Association Available online at turkjsurg.com
Keywords: Chronic anorectal disorder, sleep disturbance, sleep quality, quality of life

\section{INTRODUCTION}

Sleep is a physiological need in humans. Humans spend approximately one-third of their lifetime sleeping. Sleep follows a regular pattern; provides energy; promotes growth, development, learning, and relaxation; and is affected by many internal and external factors (1-3). Humans have physical, social, intellectual, and emotional needs. Therefore, fulfillment of the basic physical and mental needs is essential to maintain well-being. Sleep, as a fundamental need, is an important parameter that affects the quality of life (QOL) and well-being $(4,5)$. Some diseases may cause sleep disorder by inducing physical and psychological stress. Moreover, other factors, such as dietary habits, lifestyle, medication use, smoking, alcohol consumption, and illicit drug use, along with psychological and environmental factors, may affect sleep patterns (6).

Chronic diseases constitute one of the causes of sleep disorders. Chronic disease is a long-term medical condition or disease that shows slow progression and requires regular and continuous treatment and follow-up owing to its potential to cause irreversible structural or functional impairment or disability (7). Acute phases or exacerbations of chronic diseases are treated in a hospital setting, whereas most of the treatment and care is provided at home. There are many aspects that influence QOL in patients with chronic diseases. Therefore, increasing a patient's QOL is one of the fundamental objectives in the treatment of chronic diseases (8).

Chronic anorectal disorders are conditions that require continuous treatment and care, along with self-management to prevent acute complications and minimize long-term effects. Currently, chronic anorectal disorders frequently encountered in the general population emerge as an important surgical problem with a risk of recurrence and becoming chronic following both surgical and medical therapies. They also have the tendency to decrease QOL owing to poor prognosis and related complications. Among the frequently diagnosed anorectal disorders, the prevalence of chronic anal fissure is $6 \%-7 \%$, chronic hemorrhoidal disease is $45 \%$, chronic sacrococcygeal pilonidal disease is $3 \%-4 \%$, and chronic anal abscess/fistula is $4 \%-5 \%(9,10)$. Sleep-a state in which the tissues in the body undergo regeneration-is one of the fundamental daily life activities that affect the individuals' QOL and health. Chronic 
anorectal disorders may cause sleep problems by causing pain and physical disorders, resulting in anxiety and depression in the long term $(11,12)$. A review of the literature shows that whereas the relationship between sleep disorders and various other disorders is investigated, there is no sufficient research on the effects of sleep quality on QOL in patients with chronic anorectal disorders. The aim of the present study was to assess sleep quality in patients with chronic anorectal disorders, to determine the factors that might be associated with sleep quality, and to explore the relationship between sleep quality and QOL.

\section{MATERIAL AND METHODS}

This descriptive study was conducted between April 8, 2015 and April 12, 2016. The research population was composed of 284 patients who were admitted to the surgical outpatient clinics of Konya Military Hospital and who were subsequently diagnosed with one of the four most frequent anorectal disorders. Anorectal disorders comprised hemorrhoidal disease, anal fissure, anorectal abscess/fistula, and sacrococcygeal pilonidal disease. Participants who were male and female, aged $\geq 18$ years, and who had the level of education and the mental status sufficient to complete the assessment scales and questionnaires were included in the study. Informed consent was obtained from all of the patients. Data were collected from 114 patients who volunteered to participate in the study. The ethics committee approved the study (approval date: April 7, 2015; decree no. 2015/01-9). Following the diagnosis based on proctological anamnesis and physical examination conducted in the surgical outpatient clinics, the Pittsburgh Sleep Quality Index (PSQI), Short-Form Health Survey (SF-36), Beck Anxiety Inventory, and Beck Depression Inventory were administered to the patients, along with a questionnaire on their sociodemographic data, via face-to-face interviews.

Sociodemographic data included gender, age, income, marital status, educational level, medical history, alcohol consumption, smoking, and possible physical complaints. The SF-36 is used to assess QOL and was designed for use in clinical practice by the Rand Corporation in 1992 (13). It is a 36-item questionnaire with physical and mental components. The physical component consists of general health perceptions, physical functioning, role limitations because of physical health, and bodily pain subscales, whereas the mental component consists of emotional well-being, role limitations because of personal or emotional problems, energy/fatigue, and social functioning subscales. Each subscale is scored on a scale from 0 to 100 points, where " 0 " indicates a poor health status. It contains items on the perceived change in health during the past 4 weeks and past week. The validity and reliability of the Turkish version of the SF-36 were assessed by Koçyigit et al. (14).

Pittsburgh Sleep Quality Index was used to evaluate the sleep quality of patients. It was developed by Buysse et al. (15) consisting of 19 questions and 7 components to assess sleep quality during the past month. The total score is calculated using 18 items and 7 components. Each item is rated on a $0-3$ scale, and component scores are summarized to create a total PSQI score with a range of $0-21$, with higher scores indicating poor sleep quality. A total PSQI score of $<5$ indicates good sleep quality, whereas a total score of $\geq 5$ indicates poor sleep quality (15). Ağargün et al. (16) evaluated the validity and reliability of the index and found that it is applicable to the Turkish population. The sensitivity of the test is $89.6 \%$, and the specificity is $86.5 \%$.

\section{Statistical Analysis}

Frequency distribution, descriptive statistics, and cross-tabulations were created using the Statistical Package for the Social Sciences (SPSS) version 15.0 software (SPSS Inc., Chicago, IL, USA). Demographic data, descriptive findings related to disease, and PSQI and QOL scores were expressed in frequency and percentages. The chi-square test was used to assess the relationship between diagnosis and sleep quality. The independent sample t-test was used to compare different subscales of the QOL scale and sleep quality in groups. A level of 0.05 was statistically significant.

\section{RESULTS}

Table 1 shows the sociodemographic data of the participants in the study and descriptive findings related to the disease. With regard to patient demographics, $89.5 \%$ of the participants were males, $52.6 \%$ were in the $22-30$-year age group, $82.5 \%$ had moderate income, and $49.5 \%$ had undergraduate degrees. Of the patients, $38.6 \%$ were diagnosed with chronic hemorrhoidal disease, $29.8 \%$ with chronic anal fissure, $17.5 \%$ with chronic sacrococcygeal pilonidal disease, and $14.0 \%$ with chronic anorectal abscess and fistula. Of the 58 patients, 28 complained of bleeding, whereas 30 had constipation and diarrhea. With regard to treatment, $47.4 \%$ of the patients had previously undergone surgery, and $71.9 \%$ had received medical therapy (Table 1). The relationship between sleep quality and sociodemographic and descriptive variables (smoking, alcohol consumption, surgical history, and medical therapy) was evaluated using the chi-square test. There was no statistically significant relationship between sleep quality and sociodemographic and descriptive characteristics ( $p>0.05)$. The findings show that among the patients with poor sleep quality, $45.8 \%$ suffered from pain, $29.2 \%$ from constipation, and $25 \%$ from bleeding.

The findings show that 96 (84.2\%) patients had poor sleep quality, whereas 18 (15.8\%) had good sleep quality. Among the participants of the study, 24 out of 34 patients diagnosed with chronic anal fissure (70.6\%), 40 out of 44 with chronic hemorrhoidal disease $(90.9 \%), 16$ out of 20 with chronic sacrococcygeal pilonidal disease (80.0\%), and 16 with chronic anorectal abscess and fistula (100.0\%) had poor sleep quality. There was a statistically significant difference between patients with poor sleep quality and patients with good sleep quality $(p<0.05$; Table 2$)$.

The findings also show that $59.65 \%$ of the patients had no anxiety, whereas $24.56 \%$ had mild, $8.77 \%$ had moderate, and $7.02 \%$ had severe anxiety. In addition, $57.9 \%$ of the patients had no depression, whereas $33.33 \%$ had mild, $7.02 \%$ had moderate, and $1.75 \%$ had severe depression. The chi-square test showed that chronic anorectal disorders, such as chronic anal fissure, chronic hemorrhoidal disease, chronic sacrococcygeal pilonidal disease, and chronic anorectal abscess and fistula, did not show a significant relationship with anxiety and depression ( $p>0.05$ ). Moreover, $77.8 \%$ of the patients with good sleep quality based on the PSQI scores had no depression, whereas $22.2 \%$ had moderate depression. On the other hand, $43.8 \%$ of the patients with poor sleep quality had no depression, whereas $29.2 \%$ had 
Akçay et al.

Sleep quality on quality of life in anorectal disorder

mild, $22.9 \%$ had moderate, and $4.2 \%$ had severe depression $\left(\chi^{2}=0.023, p<0.05\right)$. Additionally, $55.6 \%$ of the patients with

Table 1. Sociodemographic and descriptive data of participants

\begin{tabular}{lcc} 
Gender & $\mathbf{n}$ & $\%$ \\
Female & 12 & 10.5 \\
Male & 102 & 89.5 \\
\hline
\end{tabular}

\section{Age(years)}

$\begin{array}{lcc}18-21 & 30 & 26.3 \\ 22-30 & 60 & 52.6 \\ 31-45 & 22 & 19.3 \\ \geq 45 & 2 & 1.7 \\ \text { Income level } & & \\ \text { Low } & 10 & 8.8 \\ \text { Moderate } & 94 & 82.5 \\ \text { High } & 10 & 8.8\end{array}$

\section{Educational level}

\begin{tabular}{lcc} 
Primary school & 24 & 21.1 \\
High school & 22 & 19.3 \\
Undergraduate & 56 & 49.1 \\
Postgraduate & 12 & 10.5 \\
Duration of disease & Min/max & Mean \pm SD \\
\hline Diagnosis & $1 / 5$ & $2.74 \pm 1.48$ \\
Chronic hemorrhoidal disease & $\mathbf{n}$ & $\%$ \\
Chronic anal fissure & 44 & 38.6 \\
Chronic sacrococcygeal pilonidal disease 20 & 29.8 \\
Chronic anorectal abscess and fistula & 16 & 17.5 \\
\hline
\end{tabular}

$\begin{array}{lll}\text { Complaints } & & \\ \text { Pain } & 56 & 49.1 \\ \text { Constipation/diarrhea } & 30 & 26.4 \\ \text { Bleeding } & 28 & 24.6\end{array}$

\section{Surgical history}

$\begin{array}{lcc}\text { Yes } & 54 & 47.4 \\ \text { No } & 60 & 52.6 \\ \text { Medical therapy } & & \\ \text { Yes } & 82 & 71.9 \\ \text { No } & 32 & 28.1 \\ \text { Total } & 114 & 100\end{array}$

good sleep quality according to the PSQI scores had no anxiety, whereas $33.3 \%$ had mild, and $11.1 \%$ had moderate anxiety. Moreover, $33.3 \%$ of the patients with poor sleep quality had no anxiety, whereas $20.8 \%$ had mild, $25.0 \%$ had moderate, and $20.8 \%$ had severe anxiety $\left(\chi^{2}=0.044, p<0.05\right)$.

Table 3 shows the distribution of the patients' PSQI scores according to their diagnoses. When all patients with chronic anorectal disorders are evaluated based on their total PSQI scores, it was found that the average PSQI scores of patients in all the diagnosis groups were $>5$ points. The mean PSQI scores were $9.82 \pm 4.8$ points in patients diagnosed with chronic anal fissure, $11.27 \pm 3.37$ points in patients diagnosed with chronic hemorrhoidal disease, $10.15 \pm 3.80$ points in patients diagnosed with chronic sacrococcygeal pilonidal disease, and $14.00 \pm 2.78$ points in patients diagnosed with chronic anorectal abscess and fistula (Table 3 ).

Table 4 shows the distribution of the patients' QOL scores based on their diagnoses. Various subscale scores that comprise the QOL scale are as follows: physical functioning subscale with $25.6 \pm 4.20$, role limitations because of physical health problems subscale with $6.33 \pm 1.44$, bodily pain subscale with $7.33 \pm 2.34$, perceived change in health subscale with $19.59 \pm 5.05$, energy/fatigue subscale with $14.82 \pm 4.71$, social functioning subscale with $7.12 \pm 2.08$, role limitations because of personal or emotional problems subscale with $4.57 \pm 1.27$, and emotional well-being subscale with $18.91 \pm 5.06$. In terms of QOL, all groups of patients with anorectal disorders suffered from bodily pain, energy/fatigue, impaired social functioning, and poor emotional well-being. Among these subgroups, patients with chronic sacrococcygeal pilonidal disease particularly suffered from bodily pain, whereas patients diagnosed with anorectal abscess and fistula particularly suffered from energy/fatigue, impaired social functioning, and poor emotional well-being (Table 4).

The mean QOL scores in patients with poor sleep quality $(n=96)$ were below average in all subscales of the QOL scale. There was a significant relationship between sleep quality and scores in physical functioning, role limitations because of physical health problems, bodily pain, perceived general health, and emotional well-being subscales $(p<0.005, p<0.05$, $\mathrm{p}<0.05, \mathrm{p}<0.05$, and $\mathrm{p}<0.001$, respectively; Table 5).

\section{DISCUSSION}

The present study found that $84.2 \%$ of the participants had poor sleep quality. Sleep quality was considerably impaired in all diagnosis groups, patients in all diagnosis groups scored

Table 2. Sleep quality of patients based on their diagnoses

\begin{tabular}{|c|c|c|c|c|c|c|}
\hline \multirow[b]{2}{*}{ Diagnosis } & \multicolumn{2}{|c|}{ Good sleep quality } & \multicolumn{2}{|c|}{ Poor sleep quality } & \multirow{2}{*}{$\begin{array}{c}\text { Total } \\
\mathbf{n}\end{array}$} & \multirow[b]{2}{*}{$p$} \\
\hline & $\mathbf{n}$ & $\%$ & $\mathbf{n}$ & $\%$ & & \\
\hline Chronic anal fissure & 10 & 29.4 & 24 & 70.6 & 34 & 0.023 \\
\hline Chronic hemorrhoidal disease & 4 & 9.1 & 40 & 90.9 & 44 & $<0.05^{*}$ \\
\hline Chronic sacrococcygeal pilonidal disease & 4 & 20.0 & 16 & 80.0 & 20 & \\
\hline Total & 18 & 15.8 & 96 & 84.2 & 114 & \\
\hline
\end{tabular}


Table 3. Distribution of the PSQI scores of patients based on their diagnoses

\begin{tabular}{|c|c|c|c|c|c|c|}
\hline & $\begin{array}{l}\text { Chronic } \\
\text { anal } \\
\text { fissure } \\
(n=34)\end{array}$ & $\begin{array}{l}\text { Chronic } \\
\text { hemorrhoidal } \\
\text { disease } \\
(n=44)\end{array}$ & $\begin{array}{c}\text { Chronic } \\
\text { sacrococcygeal } \\
\text { pilonidal } \\
\text { disease } \\
(n=20)\end{array}$ & $\begin{array}{l}\text { Chronic } \\
\text { anorectal } \\
\text { abscess and } \\
\text { fistula } \\
(n=16)\end{array}$ & & \\
\hline PSQI* & Mean \pm SD & Mean \pm SD & Mean \pm SD & Mean \pm SD & $\operatorname{Min} / \max$ & Mean \pm SD \\
\hline Sleep efficiency & $1.00 \pm 1.15$ & $1.00 \pm 1.09$ & $0.70 \pm 1.12$ & $1.00 \pm 1.15$ & $0 / 3$ & $0.95 \pm 1.12$ \\
\hline Sleep disturbance & $1.97 \pm 0.90$ & $2.31 \pm 0.70$ & $2.40 \pm 0.68$ & $2.87 \pm 0.34$ & $0 / 3$ & $2.31 \pm 0.77$ \\
\hline Use of sleep medication & $1.03 \pm 0.67$ & $1.02 \pm 0.50$ & $1.15 \pm 0.81$ & $1.25 \pm 0.68$ & $0 / 3$ & $1.08 \pm 0.64$ \\
\hline Daytime dysfunction & $1.79 \pm 0.77$ & $2.36 \pm 0.65$ & $1.95 \pm 0.94$ & $2.75 \pm 0.44$ & $0 / 3$ & $2.18 \pm 0.78$ \\
\hline Sleep onset latency & $1.32 \pm 0.87$ & $1.54 \pm 0.72$ & $1.50 \pm 0.82$ & $2.12 \pm 0.61$ & $0 / 3$ & $1.55 \pm 0.81$ \\
\hline Duration of sleep & $0.97 \pm 1.05$ & $1.11 \pm 0.99$ & $0.70 \pm 0.92$ & $1.50 \pm 1.26$ & $0 / 3$ & $1.05 \pm 1.05$ \\
\hline Subjective sleep quality & $1.73 \pm 0.86$ & $1.90 \pm 0.86$ & $1.80 \pm 1.00$ & $2.50 \pm 0.73$ & $0 / 3$ & $1.92 \pm 0.89$ \\
\hline Total PSQI score & $9.82 \pm 4.83$ & $11.27 \pm 3.37$ & $10.15 \pm 3.80$ & $14.00 \pm 2.78$ & $0 / 19$ & $11.03 \pm 4.05$ \\
\hline
\end{tabular}

Table 4. Distribution of the quality of life scores of patients based on their diagnoses

\begin{tabular}{|c|c|c|c|c|c|c|}
\hline \multirow[b]{2}{*}{ SF-36 Health Survey* } & \multirow{2}{*}{$\begin{array}{c}\text { Chronic } \\
\text { anal } \\
\text { fissure } \\
(n=34) \\
\text { Mean } \pm \text { SD }\end{array}$} & \multirow{2}{*}{$\begin{array}{c}\begin{array}{c}\text { Chronic } \\
\text { hemorrhoidal } \\
\text { disease } \\
(n=44)\end{array} \\
\text { Mean } \pm \text { SD }\end{array}$} & \multirow{2}{*}{$\begin{array}{c}\text { Chronic } \\
\text { sacrococcygeal } \\
\text { pilonidal } \\
\text { disease } \\
(n=20) \\
\text { Mean } \pm \text { SD }\end{array}$} & \multirow{2}{*}{$\begin{array}{c}\text { Chronic } \\
\text { anorectal } \\
\text { abscess and } \\
\text { fistula } \\
(n=16) \\
\text { Mean } \pm \text { SD }\end{array}$} & \multicolumn{2}{|c|}{ Total score } \\
\hline & & & & & $\operatorname{Min} / \max$ & Mean \pm SD \\
\hline Physical functioning & $26.06 \pm 3.04$ & $25.73 \pm 4.77$ & $25.3 \pm 5.33$ & $24.38 \pm 2.73$ & $12 / 30$ & $25.6 \pm 4.20$ \\
\hline $\begin{array}{l}\text { Role limitations because of } \\
\text { physical health problems }\end{array}$ & $6.59 \pm 1.26$ & $6.41 \pm 1.61$ & $6.20 \pm 1.58$ & $5.75 \pm 1.00$ & $4 / 8$ & $6.33 \pm 1.44$ \\
\hline Bodily pain & $7.78 \pm 2.56$ & $7.44 \pm 2.34$ & $6.59 \pm 2.17$ & $7.04 \pm 1.92$ & $2 / 12$ & $7.33 \pm 2.34$ \\
\hline General health perceptions & $21.55 \pm 3.87$ & $19.33 \pm 5.21$ & $19.44 \pm 6.00$ & $16.35 \pm 3.93$ & $9 / 30$ & $19.59 \pm 5.05$ \\
\hline Energy/fatigue & $15.30 \pm 3.82$ & $15.60 \pm 5.33$ & $14.80 \pm 5.16$ & $11.75 \pm 2.72$ & $4 / 24$ & $14.82 \pm 4.71$ \\
\hline Social functioning & $7.41 \pm 2.11$ & $7.27 \pm 2.00$ & $7.00 \pm 2.15$ & $6.25 \pm 2.11$ & $2 / 10$ & $7.12 \pm 2.08$ \\
\hline $\begin{array}{l}\text { Role limitations because of } \\
\text { personal or emotional problems }\end{array}$ & $4.64 \pm 1.34$ & $4.77 \pm 1.32$ & $4.50 \pm 1.05$ & $4.00 \pm 1.15$ & $3 / 6$ & $4.57 \pm 1.27$ \\
\hline Emotional well-being & $19.23 \pm 4.14$ & $20.09 \pm 5.31$ & $18.10 \pm 6.48$ & $16.00 \pm 2.73$ & $5 / 30$ & $18.91 \pm 5.06$ \\
\hline
\end{tabular}

Table 5. Comparison of sleep quality and various subscales of the quality of life scale

\begin{tabular}{|c|c|c|c|c|}
\hline & $\begin{array}{c}\text { Good sleep } \\
\text { quality }(n=18)\end{array}$ & $\begin{array}{c}\text { Poor sleep } \\
\text { quality }(n=96)\end{array}$ & & \\
\hline SF-36 Health Survey & Mean \pm SD & Mean \pm SD & $\mathbf{F}$ & $\mathbf{p}^{*}$ \\
\hline Physical functioning & $28.00 \pm 1.82$ & $25.10 \pm 4.33$ & 11.485 & 0.001 \\
\hline Role limitations because of physical health problems & $6.55 \pm 1.19$ & $6.29 \pm 1.48$ & 5.790 & 0.018 \\
\hline Bodily pain & $8.22 \pm 3.18$ & $7.17 \pm 2.12$ & 6.619 & 0.011 \\
\hline General health perceptions & $21.67 \pm 6.69$ & $19.21 \pm 4.63$ & 5.565 & 0.020 \\
\hline Energy/fatigue & $15.56 \pm 6.29$ & $14.68 \pm 4.38$ & 3.694 & 0.057 \\
\hline Social functioning & $7.88 \pm 2.54$ & $6.98 \pm 1.97$ & 1.049 & 3.694 \\
\hline Role limitations because of personal or emotional problems & $5.00 \pm 1.45$ & $4.50 \pm 1.23$ & 2.781 & 0.098 \\
\hline Emotional well-being & $20.33 \pm 8.33$ & $18.65 \pm 4.20$ & 19.049 & 0.000 \\
\hline
\end{tabular}

$>5$ points in PSQI, and their scores in all components of the QOL scale were below average (Tables 2-4). The mean scores of the patients with poor sleep quality were below average in all subscales of the QOL scale compared with those of patients with good sleep quality (Table 5). Sleep quality is one of the most important factors that affect QOL (17). According 
to the study by Griffin et al. (24), nonsurgical therapies have a positive effect on $\mathrm{QOL}$ in patients diagnosed with anal fissure (18). Another study found that treatment of chronic anal fissure with topical diltiazem improves patients' QOL (19). Ortiz et al. (20) reported significant improvement in QOL in patients with chronic anal fissure following internal lateral sphincterotomy. In the present study, the findings suggested that impairment in sleep quality negatively affected QOL in patients with chronic anorectal disorders.

Age, gender, smoking, and alcohol consumption are among the many factors that affect sleep quality (21-23). However, sociodemographic characteristics and descriptive features (smoking, alcohol consumption, surgical history, and medical therapy) do not significantly affect sleep quality in patients with chronic anorectal disorders. In other words, sociodemographic characteristics and descriptive features are not among the factors that affect sleep quality in patients who participated in the present study.

Another factor that affects sleep quality is the presence of comorbid psychopathology in patients with chronic anorectal disorders. A study conducted among the patients with chronic anal fissure found high rates of comorbid psychopathological disorders. The same study also reported that QOL is negatively affected by the severity of depression and anxiety, and that stress acts as both triggering and aggravating factors in patients with chronic anal fissure (18). One of the most frequent complaints in patients with psychiatric disorders is the changes in sleep quality and quantity. In addition to the concurrence of various sleep problems with psychiatric disorders, sleep problems may emerge as a characteristic symptom of psychiatric disorders. Furthermore, sleep problems are among the diagnostic features of depressive and anxiety disorders. Previous studies have indicated that $80 \%-85 \%$ of the patients with depressive disorder suffer from insomnia, whereas 15\%-20\% suffer from hypersomnia. Patients with anxiety disorder may experience problems in sleep onset latency and duration of sleep (22). In the present study, $84.21 \%$ of the participants had no or mild anxiety, and $91.23 \%$ had poor mild depression. These rates suggest that the majority of the participants had no comorbid psychiatric disorder. Therefore, it would be reasonable to argue that anxiety and depression were not among the factors that affect sleep quality in the participants of the study.

Complaints, such as pain, constipation/diarrhea, and bleeding, that result from chronic inflammatory disease in patients with chronic anorectal disorders are distressful symptoms that impair sleep quality and considerably decrease QOL (24). One study on patients with chronic anal fissure evaluated the SF$36 \mathrm{QOL}$ scale and demonstrated that the intensity of pain and bleeding has a negative effect on bodily pain and role limitations because of personal or emotional problems (18). Another study on patients with chronic anal fissure reported pain in $96.7 \%$ and bleeding in $83.3 \%$ of the patients (18). A study conducted by Griffin et al. (24) on the effects of nonsurgical treatment on the QOL of patients with anal fissure demonstrated that in patients who had nonsurgical treatment, there is a significant reduction in pain, bleeding, and irritation symptoms. Another study found that symptoms, such as pain and irritation in patients with anal fissure, negatively affect the SF-36 scores before treatment, whereas successful treatment of anal fissure decreases pain and improves QOL (19). In the present study, $49.12 \%$ of the patients had complaints of pain, $24.56 \%$ had bleeding, and $26.3 \%$ had constipation and diarrhea (Table 1 ). Therefore, we suggest that the effects of chronic diseases on QOL must be evaluated along with their effects on individuals in treatment planning, and the treatment approach must also incorporate interventions toward increasing the patients' QOL (25). In the present study, the fact that pain was the main complaint among the patients (45.8\%) with poor sleep quality suggests that sleep quality is directly associated with patients' complaints.

\section{CONCLUSION}

The current findings demonstrate that impairment in sleep quality negatively affects $\mathrm{QOL}$ in patients with chronic anorectal disorder. Therefore, improvement in sleep quality must be one of the main objectives in treating patients with chronic anorectal disorder to improve their QOL. Future research on the subject should conduct randomized, controlled studies on larger samples using polysomnography as an objective measure to assess sleep quality.

Ethics Committee Approval: Ethics committee approval was received for this study from the Ethics Committee of Konya Military Hospital (07.04.2015-2015/01.1-9).

Informed Consent: Written informed consent was obtained from patients who participated in this study.

Peer-review: Externally peer-reviewed.

Author Contributions: Concept - B.D.A., V.O.G.; Design - B.D.A., V.O.G.; Supervision - B.D.A.; Resource - B.D.A., V.O.G., S.Ö., D.A.; Materials B.D.A., V.O.G.; Data Collection and/or Processing - B.D.A., V.O.G., O.E.; Analysis and/or Interpretation - D.A.; Literature Search - B.D.A., V.O.G.; Writing Manuscript - B.D.A.; Critical Reviews - B.D.A.

Conflict of Interest: The authors have no conflicts of interest to declare.

Financial Disclosure: The authors declared that this study has received no financial support.

\section{REFERENCES}

1. Karadağ M. Classification of sleep disorders (ICSD-2). Turkiye Klinikleri Arch Lung 2007; 8: 88-91.

2. Öztürk L. An old question to be answered: Why do we sleep? İst Tıp Fak Derg 2007; 70: 114-121.

3. Özgen F. Sleep and Sleep Disorders. Psikiyatri Dünyası 2001; 5: 41-48.

4. Karadağ MG, Aksoy $M$. Sleep regulation and nutrition. Göztepe Tıp Derg 2009; 24: 9-15.

5. Kal HE. Sleep problems and associated factors in women in menopausal period (Doctoral dissertation. Selçuk Üniversitesi Sağlık Bilimleri Enstitüsü. 2011.

6. Çeviri T. The effect of passive music therapy on sleep quality in elders living in nursing facilities. J Psych Nurs 2016; 7: 55-60.

7. Özdemir Ü, Taşçı S. Psychosocial problems and care in chronic diseases. ERÜ Sağlık Bilimleri Fakültesi Derg 2013; 1: 57-69.

8. Kumsar AK, Yılmaz FT. An overview of quality of life in chronic patients. ERÜ Sağlık Bilimleri Fakültesi Derg 2014; 2: 62-70.

9. Okuş A, Karahan Ö, Eryılmaz MA, Ay AS, Sevinç B, Aksoy N. Bodur $\mathrm{S}, \mathrm{Halıc} \mathrm{AH}$. The prevalence and distribution of pilonidal disease in society according to age and sex. Selçuk Tıp Derg 2013; 29: 120-122 
10. Çayır Y. Common anorectal disorders. Türkiye Klinikleri J Family Med Spec Top 2015; 6: 78-82.

11. Menteş, Bulut, Alabaz, Leventoğlu. Türk Kolon ve Rektum Cerrahisi Derneği Benign disorders of anorectal diseases. İvedik, Ankara: 2011.

12. Goligher JC. Surgery of the anus, rectum, and colon. 5th ed. London: Balliere, Tindall; 1984

13. Bowling A. Measuring health: A review of quality of life measurement scales. 2nd ed. Philadelphia: Open University Press; 1997.

14. Koçyigit $\mathrm{H}$, Aydemir $\mathrm{O}$, Olmez N\&Memis. The validity and reliability of SF-36 in Turkey. Ege Fiz Ted Reh Derg 1999; 12: 102-106.

15. Buysse DJ, Reynolds CF, Monk TH, Berman SR, Kupfer DJ. The Pittsburgh Sleep Quality Index: A new instrument for psychiatric practice and research. Psychiatry res 1989; 28: 193-213. [CrossRef]

16. Ağargün $\mathrm{YM}, \mathrm{Kara} H$, Anlar Ö. The validity and reliability of Pittsburg Sleep Index. Türk Psikiyatri Dergisi 1996; 7: 107-111.

17. Nurcan Arat, Yıldııım N, Altay H, Şahin O, Sökmen Y. Sabah I. Clinical and echocardiographic parameters related with the physical activity habitude and sleep quality index in patients with compensated heart failure. Türkiye Klinikleri J Cardiovasc Sci 2006; 18: 196-205.
18. Arısoy Ö, Şengül N, Çakir A. Stress and psychopathology and its impact on quality of life in chronic anal fissure (CAF) patients. Int J Colorectal Dis 2016; 4: 2732-2731.

19. Tsunoda A, Kashiwagura Y, Hirose K, Sasaki T, Kano N. Quality of life in patients with chronic anal fissure after topical treatment with diltiazem. World J GastrointestSurg 2012; 4: 251-255. [CrossRef]

20. Ortiz H, Marzo J, Armendariz P, De Miguel M. Quality of life assessment in patients with chronic anal fissure after lateral internal sphincterotomy. Br J surg 2005; 92: 881-885. [CrossRef]

21. Roehr T, Roth T. Sleep, alcohol, and quality of life: sleep and quality of life in clinical medicine. In: Verster JC, Pandi- Perumal SR, Streiner DL eds. Totowa, USA: Humana Press; 2008.

22. Aydın H. Sleep and its disorders. Hekimler Yayın Birliği Ankara: 2007.

23. Abdülkadiroğlu Z, Bayramoğlu F, İlhan N. Sleep and sleep disorders. Genel Tıp Derg 1997; 7: 161-166.

24. Griffin N, Acheson AG, Tung P, Sheard C, Glazebrook C, Scholefield $\mathrm{JH}$. Quality of life in patients with chronic anal fissure. Colorectal Dis 2004; 6: 39-44. [CrossRef]

25. Ucan O, Ovayolu N. Relationship between diabetes mellitus, hypertension and obesity, and health-related quality of life in Gaziantep, a central south-eastern city in Turkey. J clinnurs 2010; 19: 2511-2519. [CrossRef] 